\title{
Role of computed tomography in evaluating asbestos related lung disease
}

\author{
S LOZEWICZ,' R H REZNEK, ${ }^{2}$ M HERDMAN, ${ }^{\prime}$ J E DACIE, ${ }^{2}$ A McLEAN, ${ }^{2}$ R J DAVIES \\ From the Departments of Respiratory Medicine, ${ }^{1}$ and Radiology, ${ }^{2}$ St Bartholomew's Hospital, London EC1 \\ $7 B E, U K$
}

ABSTRACT To find how computed tomography (CT) may be effectively used in individuals with suspected asbestos related lung disease 30 men with a history of exposure to asbestos were studied. All subjects underwent high kilovoltage posteroanterior and left lateral chest radiographs and chest CT. Eighteen were randomly selected asbestos workers referred for routine surveillance. The remaining 12 were patients who had been referred for investigation of respiratory symptoms or abnormal routine chest radiograph, or both, and found to have chest radiographic changes compatible with asbestos related lung disease. In the group referred for routine surveillance both pleural shadowing and pulmonary shadowing were shown on CT but not chest radiographs in only one case. Five were thought to have pleural shadowing on chest radiographs but this was confirmed on CT in only one case. All 12 patients referred for investigation showed pleural shadowing on chest radiographs; this was confirmed in all cases on CT which also showed unsuspected pulmonary shadowing in five cases. These findings suggest that it is not appropriate to use chest CT routinely in all asbestos workers referred for routine surveillance. When CT is used selectively in those with pleural shadowing on plain chest radiography, however, it is helpful in refuting or confirming the presence of pleural disease and may show unsuspected pulmonary shadowing.

Computed tomography (CT) is more sensitive and more specific than plain chest radiography in showing both pleural and pulmonary lesions associated with exposure to asbestos. ${ }^{1-7}$ The role of CT in evaluating asbestos related lung disease is not defined, however. The purpose of the present study was to find out how CT scanning may be used effectively in individuals with suspected asbestos related lung disease. In particular we aimed to assess its role in the routine medical surveillance of asbestos workers referred for examination under the Control of Asbestos at Work Regulations 1987, for which the minimum radiological examination currently required is a full size posteroanterior (PA) chest radiograph. ${ }^{8}$

\section{Population and methods}

We studied 30 men of whom 18 were randomly selected asbestos workers who had been referred for routine surveillance under the Control of Asbestos at Work Regulations. The remaining 12 were patients who had been referred to the department of respiratory medicine at St Bartholomew's Hospital for investigation of respiratory symptoms or abnormality detected on routine chest radiograph; they were selected for this study on the basis of their having a history of occupational exposure to asbestos and chest radiograph changes compatible with asbestos related lung disease.

The presence or absence of the following symptoms was recorded; breathlessness walking on level ground, cough on most days, and sputum production on most days for as much as three months each year. Details were also recorded of their occupational and cigarette smoking history. All subjects underwent physical examination of the respiratory system and lung function tests which included forced expiratory volume in one second $\left(\mathrm{FEV}_{1}\right)$, vital capacity (VC), total lung capacity by helium dilution (TLC), and measurement of the transfer coefficient for carbon monoxide.

A high kilovoltage PA and left lateral chest radiographs were performed in all cases. Right and left anterior oblique chest radiographs were done in 12 of the 18 workers referred for routine surveillance and in five of the 12 patients referred for investigations. 
Lozewicz, Reznek, Herdman, Dacie, McLean, Davies $\stackrel{\text { m }}{\underline{m}}$

All subjects had chest CT with a GE9800 whole body scanner. Scans were made at $1 \mathrm{~cm}$ intervals contiguously from the lung apices to the bases. All subjects were scanned in the supine position and nine unselected subjects were additionally scanned prone to look for changes in gravity dependent perfusion, which have been described in asbestos related lung disease. ${ }^{23}$ Subjects were also scanned in the prone position when shadowing was shown in dependent parts of the lung to determine whether the shadowing was gravity dependent. All the chest radiographs were interpreted by the same experienced radiologist (JED). All the scans were interpreted independently by two other radiologists (RR, AM) experienced in whole body scanning and who had no knowledge of the chest radiograph appearances. The radiologists were aware that the subjects had been exposed to asbestos but they did not know to which of the two subgroups the subjects belonged.

\section{Results}

Subject details and results of lung function tests are recorded in table 1 . None of the subjects had finger clubbing or inspiratory crackles at the lung bases.

Table 2 shows the numbers of those patients referred for investigation who showed changes compatible with asbestos related lung disease on chest radiographs or CT, or both. Pleural thickening was

Table 1 Subject details

\begin{tabular}{|c|c|c|}
\hline & $\begin{array}{l}\text { Asbestos workers } \\
\text { undergoing routine } \\
\text { surveillance } \\
(n=18)\end{array}$ & $\begin{array}{l}\text { Asbestos exposed } \\
\text { patients with } \\
\text { abnormal chest } \\
\text { radiograph } \\
(n=12)\end{array}$ \\
\hline $\begin{array}{l}\text { Age: } \\
\text { Mean } \\
\text { Range }\end{array}$ & $\begin{array}{l}31 \\
14-52\end{array}$ & $\begin{array}{l}59 \\
45-78\end{array}$ \\
\hline $\begin{array}{l}\text { Time since first exposur } \\
\text { Mean } \\
\text { Range }\end{array}$ & $\begin{array}{l}7 \\
1-30\end{array}$ & $\begin{array}{l}33 \\
18-64\end{array}$ \\
\hline $\begin{array}{l}\text { Duration of exposure (y } \\
\text { Mean } \\
\text { Range }\end{array}$ & $\begin{array}{l}7 \\
7 \cdot 1-30\end{array}$ & $\stackrel{14}{0 \cdot 25-30}$ \\
\hline $\begin{array}{l}\text { Cigarette smoking: } \\
\text { Current } \\
\text { Ex } \\
\text { Never } \\
\text { Respiratory symptoms: } \\
\text { any or all of } \\
\text { breathlessness, cough, } \\
\text { or sputum }\end{array}$ & $\begin{array}{r}10 \\
1 \\
7 \\
6\end{array}$ & $\begin{array}{l}6 \\
6 \\
0 \\
9\end{array}$ \\
\hline $\begin{array}{l}\text { Lung function as mean } \\
\text { \% predicted (SEM) } \\
\text { FEV } \\
\text { VC } \\
\text { TLC } \\
\text { KCO }\end{array}$ & $\begin{array}{r}106(2 \cdot 43) \\
106(2 \cdot 39) \\
101(3 \cdot 38) \\
87(3 \cdot 38)\end{array}$ & $\begin{array}{l}65(4.25) \\
73(5.97) \\
80(6.06) \\
99(6.06)\end{array}$ \\
\hline
\end{tabular}

Table 2 Radiological findings in 12 patients exposed to asbestos with chest radiograph abnormalities compatible withasbestos related lung disease

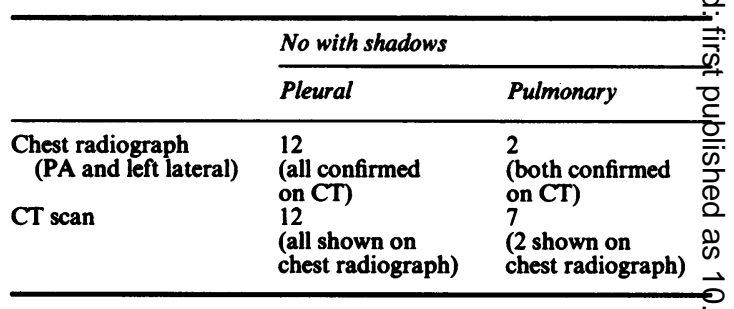

seen in all 12 patients on both chest radiographs and CT. Asbestosis was thought to be present on chesto radiographs in only two patients and in each case this was confirmed on CT. CT also showed pulmonary shadowing compatible with asbestosis in a further five? of the 12 patients (see fig 1). Five of this group had right and left oblique chest radiographs and in two of these the oblique films showed pulmonary shadowing that was confirmed on CT but not evident on the PA? or left lateral chest radiograph. In one of the five $\vec{r}$ oblique films failed to show pulmonary shadowingo that was evident on CT.

Table 3 shows the numbers of asbestos workers referred for routine surveillance who showed changes compatible with asbestos related lung disease on chest radiograph or CT, or both. The chest radiograph wissog thought to show pleural shadows in five workers bat only one of these showed pleural thickening on CT. $\bar{\oplus}$ in view of the accuracy with which pleural thickening is seen on CT it is probable that the apparent pleurato shadows on chest radiograph in four of these caseso were false positive findings. In two of these four CT을 showed subpleural fat at a site corresponding to the $\vec{\circ}$ radiograph appearances of pleural thickening. PleuraB thickening was shown on CT in two workers and in one of these two pleural shadowing was also seen onp chest radiograph. Therefore, pleural thickening waso shown on CT but not chest radiograph in only one of this group. Furthermore, pulmonary shadowing com-응 patible with asbestosis was shown on CT in only one? worker (fig 2). Right and left oblique chesto

Table 3 Radiological findings in 18 asbestos workers referred for routine surveillance

\begin{tabular}{cll}
\hline & No with shadows & \\
\cline { 2 - 4 } & Pleural & Pulmonary \\
\hline $\begin{array}{c}\text { Chest radiograph } \\
\text { (PA and left lateral) }\end{array}$ & $\begin{array}{l}5 \\
\text { (one confirmed } \\
\text { on CT) }\end{array}$ & $\begin{array}{l}1 \\
\text { (not confirmed } \\
\text { on CT) } \\
\text { Computed tomography }\end{array}$ \\
$\begin{array}{l}2 \\
\text { (1 shown on } \\
\text { chest radiograph) }\end{array}$ & $\begin{array}{l}1 \\
\text { (not shown on } \\
\text { chest radiograph) }\end{array}$
\end{tabular}




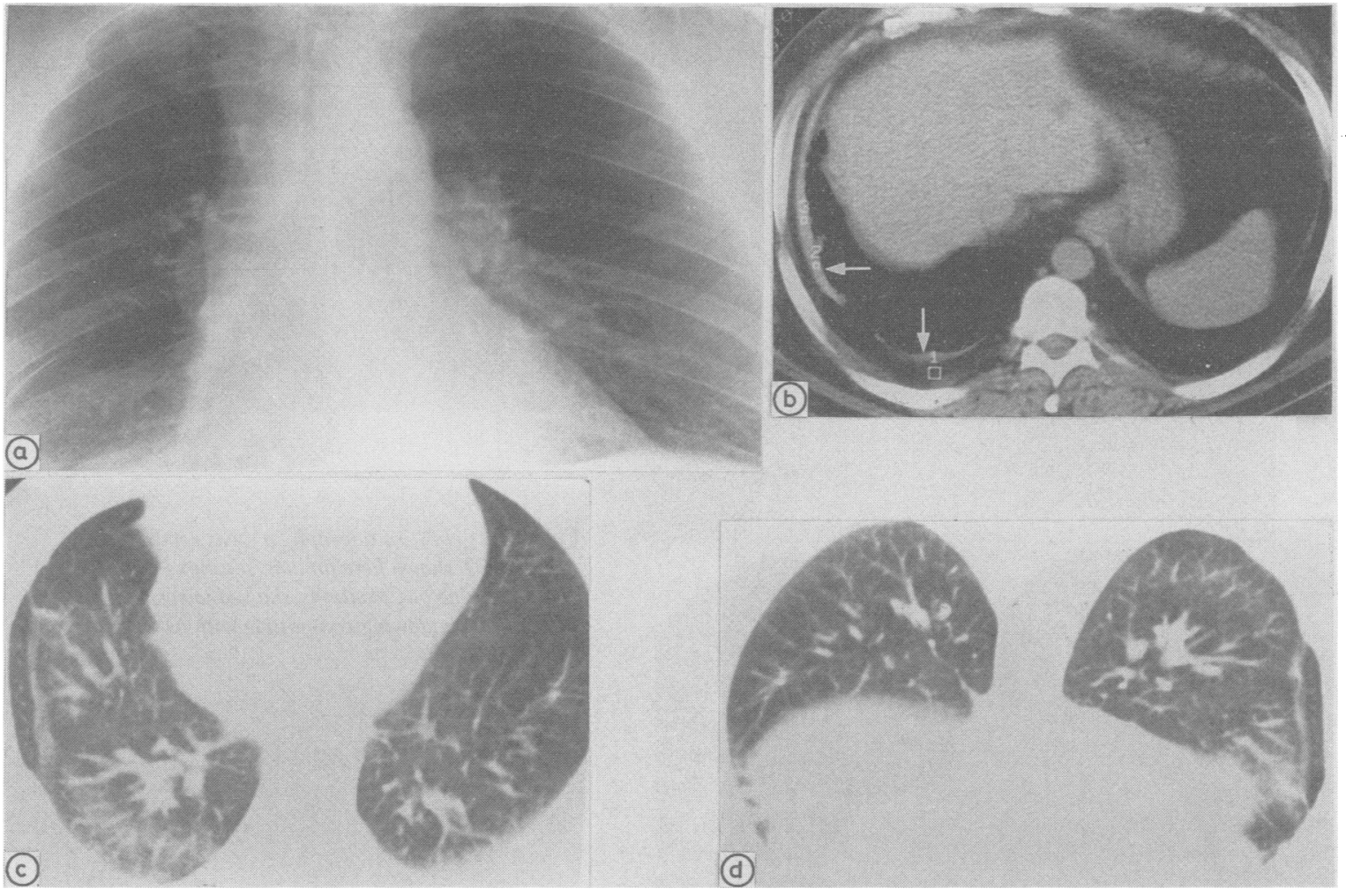

Fig 1 Chest radiograph (a) in this subject was reported to show pleural shadowing in right lower zone. Lungs were considered normal. CT shown on soft tissue settings (b) confirmed presence of pleural thickening (arrows) with subpleural fat. In supine (c) and prone (d) positions unsuspected interstitial shadowing compatible with asbestosis was seen when viewed on lung settings.

radiographs were performed in 12 of this group and they added no additional information to that already obtained with the PA and left lateral films.

In the group of 30 subjects considered as a whole 14 had pleural thickening evident on CT; the pleural changes were bilateral in 11 . Of the three with unilateral pleural thickening, one had a histologically proved mesothelioma and two had additional bilateral pulmonary shadowing compatible with asbestosis. In no case was pleural shadowing explicable on the basis of previous infection or trauma. Eighteen subjects had prone as well as supine scans and none of these showed abnormalities in gravity dependent perfusion. Table 4 compares the details of the subjects showing scan evidence of pleural or pulmonary asbestos related lung disease, or both, with those whose scan was normal; although the 14 subjects in the group with pleural or parenchymal shadowing, or both, had significantly

Table 4 Clinical findings in 30 subjects exposed to asbestos

\begin{tabular}{|c|c|c|c|}
\hline & $C T$ normal $(n=16)$ & $\begin{array}{l}\text { CT pleural or pulmonary } \\
\text { shadowing or both }(n=14)\end{array}$ & p Value \\
\hline $\begin{array}{l}\text { Time since first known occupational exposure (y) (SEM) } \\
\text { Duration of exposure (y) (SEM) } \\
\text { Respiratory symptoms: any or all of breathlessness, cough, or sputum. } \\
\text { (No(\%)) } \\
\text { Lung function \% predicted (SEM): }\end{array}$ & $\begin{array}{l}6 \cdot 0(1 \cdot 67) \\
5 \cdot 58(1 \cdot 72) \\
6(38)\end{array}$ & $\begin{array}{l}30 \cdot 8(4 \cdot 23) \\
16 \cdot 3(3 \cdot 17) \\
9(64)\end{array}$ & $\begin{array}{l}<0.0001 \\
<0.01 \\
\text { NS }\end{array}$ \\
\hline $\begin{array}{l}\text { FEV, } \\
\text { VC } \\
\text { TLC } \\
\text { KCO }\end{array}$ & $\begin{array}{l}106(2 \cdot 7) \\
107(2 \cdot 52) \\
101(3 \cdot 85) \\
87(3 \cdot 83)\end{array}$ & $\begin{array}{l}73(5 \cdot 50) \\
79(5 \cdot 59) \\
83(5 \cdot 48) \\
97(5 \cdot 34)\end{array}$ & $\begin{array}{l}<0.0001 \\
<0.0001 \\
<0.05 \\
\text { NS }\end{array}$ \\
\hline
\end{tabular}

VC, TLC, KCO, see table 1. 

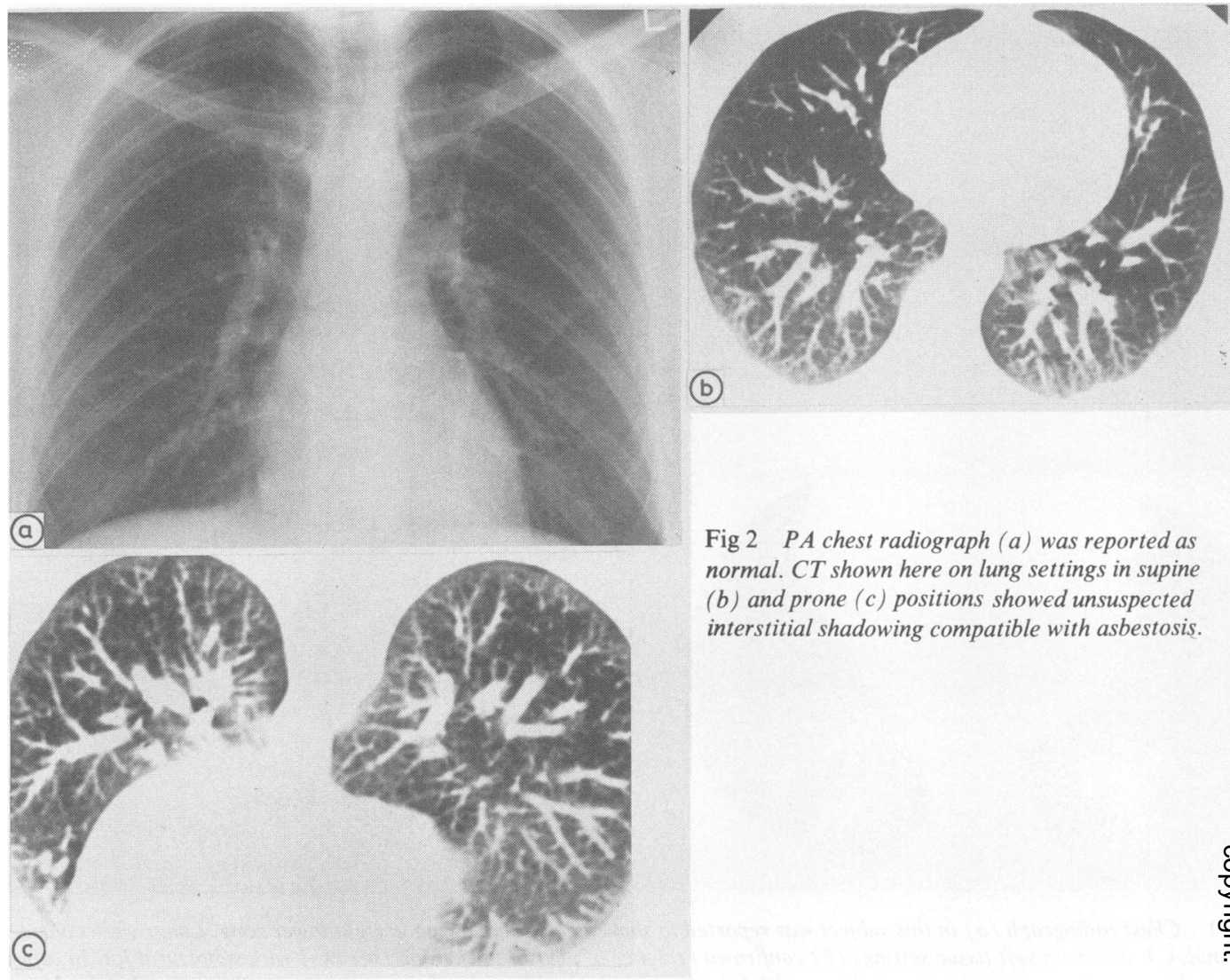

Fig 2 PA chest radiograph (a) was reported as normal. $C T$ shown here on lung settings in supine (b) and prone (c) positions showed unsuspected interstitial shadowing compatible with asbestosis.

$(<0.05)$ smaller lung volumes, seven had values within two standard deviations of predicted and would therefore be assessed as within the normal range.

\section{Discussion}

In the group of 18 asbestos workers referred for routine surveillance only one showed pleural shadowing on CT which was not seen on chest radiograph. Similarly only one showed pulmonary shadowing on CT which was not seen on chest radiograph. The cost/ benefit ratio for the routine use of CT in this group is therefore likely to be high, and the results suggest that it is not appropriate to use scanning in all workers referred for routine surveillance under the Control of Asbestos at Work Regulations. High resolution CT (HRCT) has recently been found to be more sensitive than conventional CT in detecting both pleural and pulmonary shadowing in patients with asbestosis; however, the difference in detection rates was not substantial and HRCT was less effective at showing diffuse pleural thickening, probably because of limitations imposed by the sampling technique required in
HRCT scanning. It is unlikely, therefore, that HRC市 would be more useful than conventional CT in the routine surveillance of asbestos workers.

CT showed that four of the 18 workers referred for routine surveillance had false positive shadowing of chest radiograph (table 3). In two of these four, scanis showed subpleural fat at a site corresponding to the radiograph appearances of pleural thickening. Other studies have shown the value of scans in eliminating false positive diagnoses of asbestos related pleura. disease. ${ }^{135610}$ In all 12 patients referred for invest? gation scanning confirmed the presence of pleurar shadowing seen on chest radiograph. These findings taken together indicate that when scanning is use selectively in those with pleural shadowing on chest. radiograph, it is useful in refuting or confirming thies presence of pleural disease.

The 12 patients referred for investigation all showeक pleural shadowing on chest radiographs but only two showed pulmonary shadowing, which was seen on CF in seven cases. This suggests that when patients exposed to asbestos are found to have pleural shadowi ing on chest radiograph, CT often shows unsuspected 
pulmonary shadowing. These findings may not apply to workers screened under the current regulations who are likely to have had a shorter period of exposure to asbestos (table 1) and who are more likely to have used protective measures, since their exposure began more recently (table 1 ).

Gravity dependent increased density visible on CT may be due to a combination of distended blood vessels and lung from which air has been resorbed'; it has been shown at the lung bases in approximately $30 \%$ of non-asbestos exposed subjects scanned supine but disappears in the prone position. ${ }^{9}$ We routinely performed prone as well as supine scans in those with pulmonary shadowing to exclude the possibility that the observed changes were gravity dependent. $\mathrm{Kreel}^{2}$ and Katz and Kreel ${ }^{3}$ have described loss of the normal effect of gravity in causing increased perfusion in dependent parts of the lung in some patients with asbestos related pulmonary shadowing, sometimes in the absence of other evidence of interstitial fibrosis; it was proposed that this alteration in gravity dependent perfusion might be due to some loss of the pulmonary capillary bed as a result of interstitial fibrosis. We could find no abnormalities in gravity dependent perfusion in 18 subjects, including eight with pulmonary shadowing, who had prone as well as supine CT.

The additional use of oblique chest radiographs can increase the frequency of demonstration of asbestos related abnormalities when compared with PA films alone. ${ }^{11-13}$ We obtained oblique chest radiographs in 12 of the group referred for routine surveillance and they added no additional information to that already with PA and left lateral films; furthermore, they did not show pulmonary shadowing in the one subject in whom this was proved on CT. In the group referred for investigation oblique radiographs were obtained in five patients and two of these showed pulmonary shadowing that was not evident on PA or left lateral films. One of these five, however, had pulmonary shadowing on CT that was not evident on oblique, PA, or left lateral chest radiographs. These results suggest that CT is more sensitive than plain chest radiography, including oblique films, in detecting pulmonary shadowing.

In the group of 30 subjects considered as a whole there was a significant association between the presence of CT pleural or pulmonary shadowing or both and low lung volumes. In half the subjects with abnormal CT, however, all lung function measure- ments including lung volumes and transfer coefficient for carbon monoxide were within two standard deviations of the predicted value and would therefore be judged normal. The presence of normal lung function in an individual does not therefore preclude the possibility of CT showing asbestos related lung disease.

This study shows that it is not justified to use CT routinely in the medical surveillance of asbestos workers referred under the Control of Asbestos at Work Regulations 1987. Nevertheless, when CT is used selectively in those with pleural shadowing on plain chest radiography, it is helpful in refuting or confirming the presence of pleural disease and may show unsuspected pulmonary shadowing.

\section{References}

1 Friedman AC, Fiel SB, Fisher MS, Radecki PD, Lev-Toaff AS, Caroline DF. Asbestos-related pleural disease and asbestosis: a comparison of CT and chest radiography. Am J Radiol 1988;150:269-75.

2 Kreel L. Computer tomography in the evaluation of pulmonary asbestosis. Preliminary experience with the EMI general purpose scanner. Acta Radiologica: Diagnosis 1976;17:405-12.

3 Katz D, Kreel L. Computed tomography in pulmonary asbestosis. Clin Radiol 1979;30:207-13.

4 Raithel HJ, Valentin H. Computertomographische Untersuchungen bei Patienten mit Asbestose und Silikose. Prax Klin Pneumol 1983;37:1119-29.

5 Fourio M, Dongay G, Levade M, Carles P, Bollinelli R, Putois J. Apport de la tomodensitometrie dans la pathologie pleuropulmonaire de l'amiante. J Radiol 1984;65:335-9.

6 Dongay G, Levade M, Lauque D, Carles P, Bollinelli R. Tomodensitometrie de la pathologie pleuro-pulmonaire de l'amiante. Rev Mal Respir 1985;2:31-6.

7 Maffessanti M, De Zotti R. Lo studio radiologico delle placche pleuriche nell'asbestosi. Radiol Med 1984;70:825-9.

8 Control of asbestos at work regulations. London: HMSO, 1987.

9 Aberle DR, Gamsu G, Ray CS, Feuerstein IM. Asbestos-related pleural and parenchymal fibrosis: detection with highresolution CT. Radiology 1988;166:729-34.

10 Leipner N, Brecht G, Holle JP, Lackner K, Ehlenz P, Magnussen H. Asbestose. Computertomographie im vergleich mit der konventionellen rontgendiagnostik. Fortschr Geb Rontgenstr 1984;141:275-84.

11 Reger RB, Ames RG, Merchant JA, et al. The detection of thoracic abnormalities using posterior-anterior (PA) vs PA and oblique roentgenograms. Chest 1982;81:290-5.

12 Bégin R, Boctor M, Bergeron D, et al. Radiographic assessment of pleuropulmonary disease in asbestos workers: posteroanterior, four view films, and computed tomograms of the thorax. $B r J$ Ind Med 1984;41:373-83.

13 Fletcher DE, Edge JR. The early radiological changes in pulmonary and pleural asbestosis. Clin Radiol 1970;21:355-65. 